\title{
Design of control system for Corn harvester cutting table
}

\author{
Song Xiangwen ${ }^{1, a}$, Cao Shukun ${ }^{2}{ }^{2}$ (borresponding author), Wang Chong ${ }^{3, c}$
}

\author{
Cui $Y i^{4, d}$ \\ ${ }^{1}$ Nanxinzhuang West Road 336Jinnan, School of Mechanical Engineering, University of Jinan, \\ Jinan 250022, Shandong Province, China \\ ${ }^{2}$ Nanxinzhuang West Road 336Jinnan, School of Mechanical Engineering, University of Jinan, \\ Jinan 250022, Shandong Province, China \\ ${ }^{3}$ Nanxinzhuang West Road 336Jinnan, School of Mechanical Engineering, University of Jinan, \\ Jinan 250022, Shandong Province, China \\ ${ }^{4}$ Nanxinzhuang West Road 336Jinnan, School of Mechanical Engineering, University of Jinan, \\ Jinan 250022, Shandong Province, China \\ a751937831@qq.com b87756997@qq.com c535756212@qq.com d328368596@qq.com
}

Keywords: hydraulic control; adjustable row spacing; Stepless-speed; folding of the cutting table Abstract. In this paper, the control of all the movements of the corn harvester cutting table is based on hydraulic, PLC is used as the controller of the whole machine, The hydraulic component is used to control the folding of the cutting table, the adjustable row spacing and the rotation of the twisting and stripping roller, Mainly considering the hydraulic parts arranged more freedom and convenience, to some extent save space, and the use of hydraulic program reliability is relatively strong, can be very good realization of stepless speed regulation and other advantages.

\section{Introduction}

The corn harvester in our country was backward in the early days of the founding of the people's Republic of China. At first, mainly in the backpack, the corn harvester harvest generally low efficiency, with the continuous development of agricultural technology, the old model of carrying out of the market gradually, a new self-propelled corn harvester has been hot, the rapid rise in sales to become the mainstream of corn harvester.Compared with developed countries, the development of harvesting machinery in our country is relatively late, and there are still a lot of problems in manufacturing and production technology. As a whole, it is still no mature enough.

With the development and in order to be better adapt to China's corn planting habits, in order to adapt to the different row spacing, the continuous expansion of China's corn harvester cutting, so as to adapt to the more widely spaced. One of the most representative is the guide rod no row corn harvester Tianjin Fukang agricultural development limited company development, this machine uses a reel forced feeding device, guide rod installation with a stripping mechanism, realize the cutting function of can be adjusted ${ }^{[7]}$, but the structure of automation high, the structure is complex. In this paper, the control of new corn harvester cutting table, selection of PLC controller, because it is reliable, easy to operate and easy to maintain. PLC with the fault detection function, which is easy to handle after troubleshooting, and can also be flexibly incorporated into the peripheral fault diagnosis program to realize the monitoring of the harvester. PLC hardware can be built quickly 
through standard modules, and software can be changed at any time through ladder diagrams. For intelligent agricultural machinery products, especially for test machines, the use of PLC control is a good choice.

\section{The hydraulic system control scheme}

The automatic alignment of the cutting table, the folding, the roll of the picker roll, and the rotation of the auger section are all dependent on the hydraulic system. Because of the design of cutting machine is highly modular products, the use of hydraulic system can be more flexible to arrange various hydraulic components, so as to ensure the greatest degree of header design without interference, and the use of hydraulic system is more convenient, the reaction speed is faster and easier to achieve stepless speed regulation, reliability of the hydraulic system. The service life of the cutting table increases to a certain extent, there is a very important point is the cutting table hydraulic control more easy to realize automation control.

\section{Parameters and selection of main hydraulic components}

The main functions of the hydraulic circuit are the automatic alignment, folding, the rotation of the spike roller and the rotation of the twisting part of the cutting table. In this paper, the design speed of the auger is $200 \mathrm{r} / \mathrm{min}$, and the single row power is generally $7 \mathrm{KW}$. The speed ratio of the stripper roller is $2.25: 1$, the speed ratio of the straw to chain is $0.85: 1$, and the maximum pressure under the hydraulic system is not more than $16 \mathrm{MPa}$. The main parameters of the hydraulic cylinder are shown in table 1.1 .

Table 1.1 Main parameters of hydraulic cylinder

\begin{tabular}{cccc}
\hline Name & Quantity & $\begin{array}{c}\text { length of } \\
\text { travel/mm }\end{array}$ & $\begin{array}{c}\text { cylinder } \\
\text { diamete/mm }\end{array}$ \\
\hline $\begin{array}{c}\text { Cutting table folding } \\
\text { cylinder }\end{array}$ & 2 & 713 & 80 \\
$\begin{array}{c}\text { Row spacing regulating } \\
\text { cylinder }\end{array}$ & 8 & 200 & 50 \\
Integral offset cylinder & 1 & 800 & 70 \\
\hline
\end{tabular}

It is known that the speed of spike roller motor is $524 \mathrm{rpm}$, and the power is $7 \mathrm{KW}$, According to $P=\frac{T \cdot \mathrm{n}}{9550}$, calculate the motor torque is $127.6 \mathrm{~N} . \mathrm{m}$, the final choice is the United States White WS80 type cycloid motor; Auger rotation of the motor speed is $200 \mathrm{rpm}$, power is $2 \mathrm{~kW}$, according to the relationship between power and the torque to calculate the motor torque is $95.5 \mathrm{kw}$, the final selection of the White type cycloid motor WR40. The basic parameters and selection of the stripper roller motor and the auger motor are shown in table 1.2.

Table 1.2 Motor main parameters and motor selection

\begin{tabular}{cccccc}
\hline Name & Model & $\begin{array}{c}\text { output } \\
\text { volume } \\
\text { cc/r }\end{array}$ & $\begin{array}{c}\text { Flow } \\
\text { L/min }\end{array}$ & $\begin{array}{c}\text { Set flow } \\
\text { L/min }\end{array}$ & $\begin{array}{c}\text { Set pressure } \\
\text { bar }\end{array}$ \\
\hline Picker roll motor & WS80 & 713 & 79 & 138 & 210 \\
Auger motor & WS40 & 200 & 40 & 9 & 150 \\
\hline
\end{tabular}


The basic parameters and flow settings of each cylinder are shown in table 1.3, table 1.4 and table 1.5.

Table 1.3 Parameters of adjusting cylinder parameters of stripper roll spacing

\begin{tabular}{cccccc}
\hline $\begin{array}{c}\text { cylin } \\
\text { der } \\
\text { diameter } \\
(\mathrm{mm})\end{array}$ & $\begin{array}{r}\text { rod } \\
\text { diameter } \\
(\mathrm{mm})\end{array}$ & $\begin{array}{c}\text { Trip } \\
(\mathrm{mm})\end{array}$ & $\begin{array}{c}\text { Flow } \\
(\mathrm{L} / \mathrm{min})\end{array}$ & $\begin{array}{r}\text { Stretch } \\
\text { out time(s) }\end{array}$ & $\begin{array}{c}\text { Return } \\
\text { time(s) }\end{array}$ \\
\hline 50 & 30 & 200 & 5 & 9.04 & 6.03 \\
\hline
\end{tabular}

Table 1.4 Parameters of stripper roll offset cylinder

\begin{tabular}{cccccc}
\hline $\begin{array}{c}\text { cylinder } \\
\text { diameter } \\
(\mathrm{mm})\end{array}$ & $\begin{array}{c}\text { rod } \\
\text { diameter } \\
(\mathrm{mm})\end{array}$ & $\begin{array}{c}\text { Trip } \\
(\mathrm{mm})\end{array}$ & $\begin{array}{c}\text { Flow } \\
(\mathrm{L} / \mathrm{min})\end{array}$ & $\begin{array}{c}\text { Stretch out } \\
\text { time }(\mathrm{s})\end{array}$ & $\begin{array}{c}\text { Return } \\
\text { time }(\mathrm{s})\end{array}$ \\
\hline 70 & 50 & 800 & 20 & 18.47 & 9.05 \\
\hline
\end{tabular}

Table 1.5 Parameters of folding cylinder of cutting table

\begin{tabular}{cccccc}
\hline $\begin{array}{c}\text { cylinder } \\
\text { diameter } \\
(\mathrm{mm})\end{array}$ & $\begin{array}{c}\text { rod } \\
\text { diameter } \\
(\mathrm{mm})\end{array}$ & $\begin{array}{c}\text { Trip } \\
(\mathrm{mm})\end{array}$ & $\begin{array}{c}\text { Flow } \\
(\mathrm{L} / \mathrm{min})\end{array}$ & $\begin{array}{c}\text { Stretch out } \\
\text { time }(\mathrm{s})\end{array}$ & $\begin{array}{c}\text { Return } \\
\text { time }(\mathrm{s})\end{array}$ \\
\hline 80 & 50 & 713 & 20 & 21.5 & 13.1 \\
\hline
\end{tabular}

Stripper roller hydraulic cylinder bore $40 \mathrm{~mm}$ stroke is $200 \mathrm{~mm}$, using HSG40, cylinder, cylinder liner with Bush Earrings, threaded joint bearing piston rod, oil outlet for internal thread style, maximum pressure $16 \mathrm{MPa}$, are placed on the lower pick spike roller gear box in combination. The style of the offset stripper roller is the same as that of the stripper cylinder stroke is $1000 \mathrm{~mm}$, the HSG80 cylinder bore $80 \mathrm{~mm}$. The folding cylinder style and snapping roller cylinder style is the same, need about one on each side, bore $80 \mathrm{~mm}$ stroke 740mm, HSG80 cylinder, selection.

\section{Design of Hydraulic control circuit}

In the design of hydraulic control circuit, because the large number of hydraulic motor is required, in order to make the loss of hydraulic oil is not too large, the 9 hydraulic motors are divided into 3 groups, 3 in each group, and set the 3 synchronous diffluence motor in three branch. Synchronous diffluence motor are gear type, and its shape is similar to multi gear pump gear motor, it will at least two groups in series, so that they maintain the same speed, when the oil hydraulic pump, can be flexibly set according to the proportion of allocation of oil supply to the actuator, in this process. Can be done completely without interference actuator pressure value. In the circuit of the stripper roller oil tank, a diversity flow valve is needed to balance the oil in the branch, and the differential flow valve controls the two cylinders or hydraulic motors in the hydraulic synchronous system to keep them at the same speed.

According to the functional requirements of the new corn harvester cutting platform, the hydraulic circuit diagram as shown in Fig1.1 is designed 


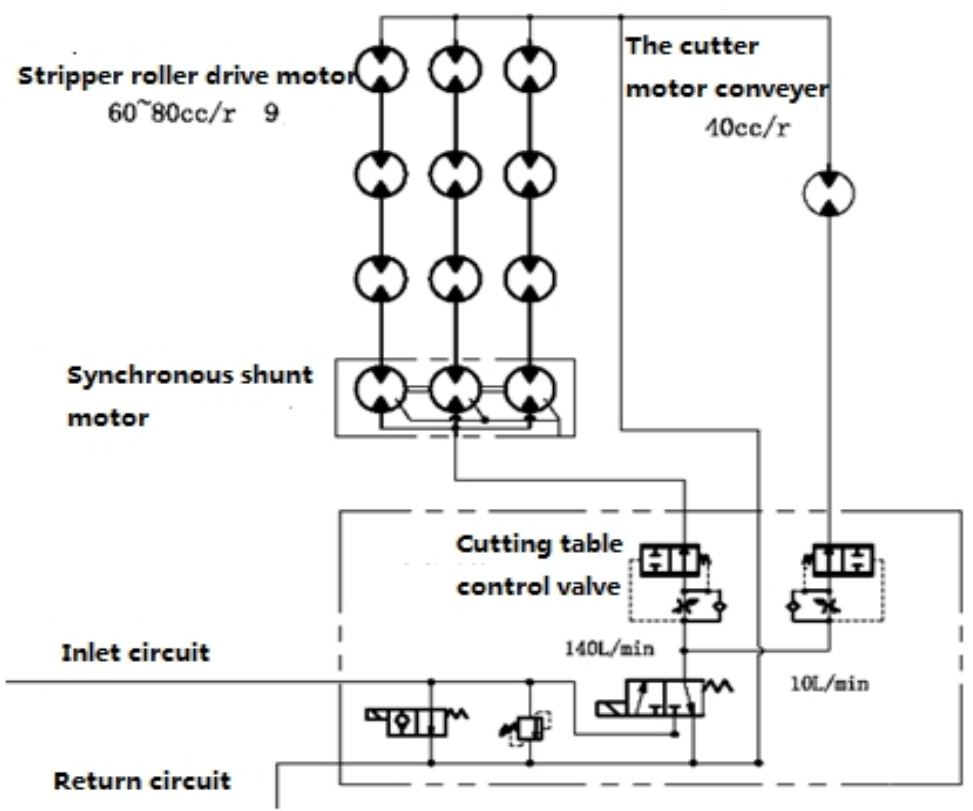

(a) Motor drive circuit

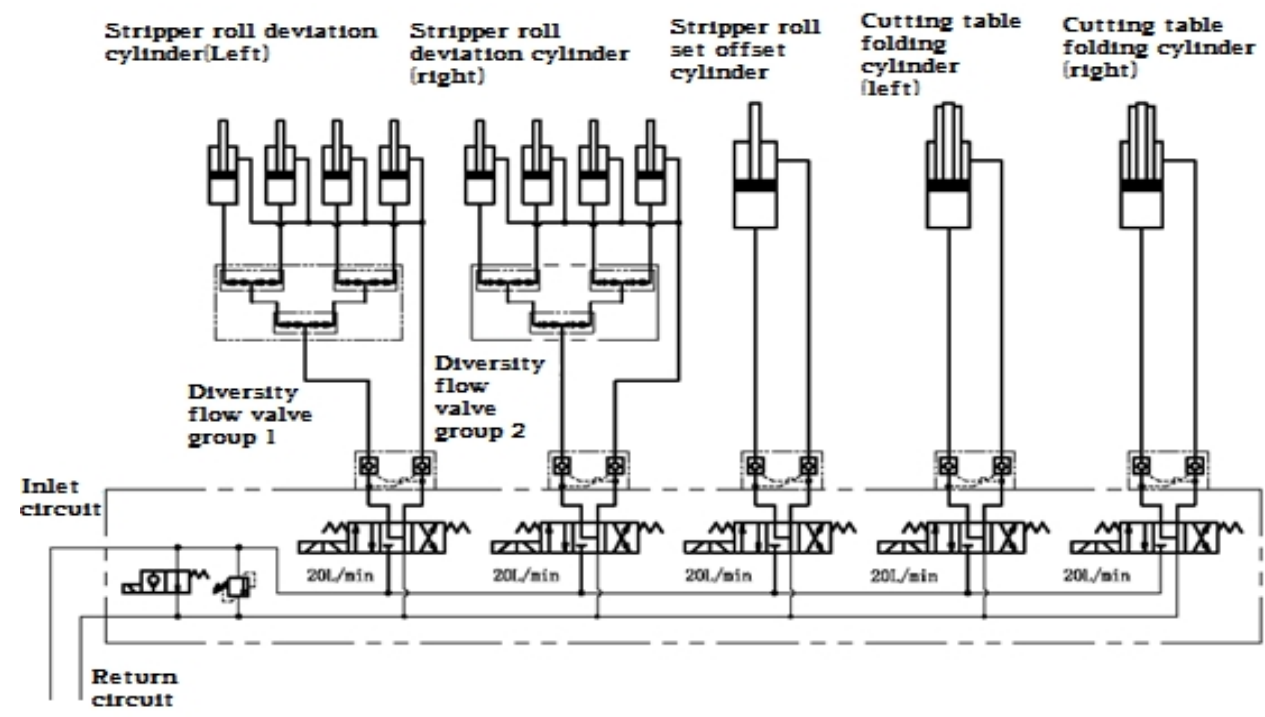

(b) Hydraulic cylinder drive circuit

Fig 1.1 Hydraulic circuit design

\section{Design of electrical system}

\section{Selection of electrical components}

In this paper, the PLC is chosen as a controller of electric control of the new corn harvester cutting table because of the ease of operation of PLC.The real-time and reliability of the PLC controller are relatively high. The configuration of the system is convenient and flexible, and the modular structure is adopted. The installation, control and maintenance are more convenient. It is suitable for the control of a large corn harvester, and can control the corn harvester well, complete the harvesting operation, and detect the faults, etc..

In this paper, OMRON PLC is used as the host computer, in which CPU uses the OMRON $\mathrm{CJ} 2 \mathrm{M}$ series, and $\mathrm{CJ} 2 \mathrm{M}$ and $\mathrm{CJ} 1 \mathrm{M}$ have better performance and capacity. Each CPU can have 40 
I/O units, and the pulse I/O module can implement position control on any CPU. You can also use table 1.6 as shown.

Table 1.6 Hardware configuration of electrical system

\begin{tabular}{ccc}
\hline $\begin{array}{c}\text { Serial } \\
\text { number }\end{array}$ & Product Name & Model \\
\hline 1 & CPU & CJ2M-CPU31 \\
2 & POWER & CJ1W-PD025 \\
3 & INPUT & CJ1W-ID211 \\
4 & OUTPUT & CJ1W-OC211 \\
5 & Analog quantity & CJ1W-AD081-V1 \\
6 & Analog quantity & CJ1W-DA041-V1 \\
7 & Bus unit & CJ1W-SCU41-V1 \\
8 & Touch screen & NB10 \\
\hline
\end{tabular}

\section{Design of control scheme}

In this paper, the data processed by image processing is transmitted to PLC directly through PC. Using OMRON PLC programming software CXProgrammer programming, in the installation of CX-One will automatically install the driver, or in connection with PLC and PC, the computer will prompt to find new hardware, and automatically install the drive. The design can be directly through the serial port and PLC communications. The basic structure of the hardware connection is shown in Fig 1.2.

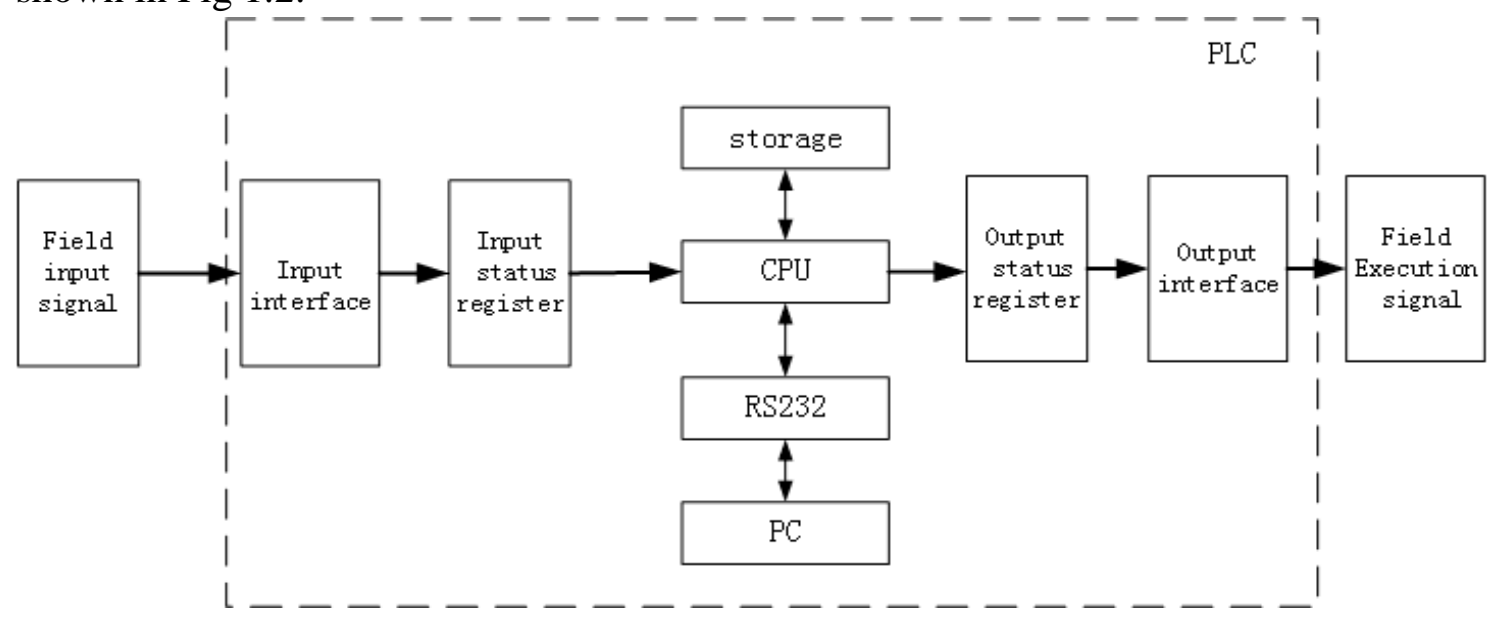

Fig1.2 PLC basic structure diagram

The whole cutting table adopts hydraulic control. When PLC controls the cutting table, it mainly controls the opening and closing of the hydraulic valve on the cutting table, so as to realize the different functions of the cutting table.In the design of the cutting table, there are three hydraulic cylinders equipped with displacement sensors, used to collect the displacement of the hydraulic cylinder. Two of them were placed in fourth from the left (used to measure the left fourth group and fifth group of snapping roll distance between) and fifth (used to measure the left fifth group and sixth group of snapping roll distance between the hydraulic cylinder) for real-time monitoring of the distance between two groups of snapping roll. The other is placed on the bias cylinder of the cutting table to prevent the offset of the table when the stroke is too large to prevent the bias of the cutting table. When the hydraulic cylinder is adjusted, the left hydraulic cylinder and the left supporting 
frame of the cutting platform are collided. In order to ensure the 8 pitch adjusting hydraulic cylinder can ensure the stability and reliability of the movement, in the regulation, the 8 hydraulic cylinders with adjustable row spacing are divided into two groups, the 4 on the left as a group, the 4 on the right as a set, and the two hydraulic cylinders are controlled by a switch respectively. When adjusting the hydraulic cylinders and motors of the cutting table, the control process is divided into the following sections:

(1) If the distance value passed by PC to PLC is equal to or less than $450 \mathrm{~mm}$, the folding hydraulic cylinder does not need to be unfolded, and all the motors are directly opened for harvesting operation;

(2) If the PC passed to the PLC distance is greater than $450 \mathrm{~mm}$, less than $550 \mathrm{~mm}$, while the left side folding hydraulic cylinder, unfolding the left cutting table, and then control the bias cutting table hydraulic cylinder to achieve the overall elongation, the 9 sets of rollers at the same time to shift to the left $800 \mathrm{~mm}$. At this time, the roller group is shifted to the left of the cutting table to the whole, and when the sensor installed on the left is smaller than the setting value, the movement of the stripper roller and the displacement of the oil cylinder are stopped, and the utility model has the function of protection. And then to the left ear picking roller combination as a benchmark, adjusting the 8 hydraulic cylinder stroke, until the sensor transfer value is equal to the PC values passed to PLC, adjust the spacing adjustment, after the completion of the volume control switch of the motor, the motor starts to work all;

(3) If the PC passed to the PLC distance is greater than 550mm, the left and right sides of the folding hydraulic cylinder are all expanded, and the left and right cutting tables are all flattened, and then the hydraulic cylinder of the cutting table is controlled to elongate, and the whole 9 groups of rollers are moved to the left at the same time, and the $800 \mathrm{~mm}$ is moved to the left.And then to the left ear picking roller combination as a benchmark, adjusting the 8 hydraulic cylinder stroke, until the sensor transfer value is equal to the PC values passed to PLC, adjust the spacing adjustment, after the adjustment is completed, control the amount of motor switch, so that all the motors begin to work and begin harvesting;

(4) The corn harvester stage after harvest, need to stop auger motor and stripper roller combination motor work, after all the motor stopped working, and then control the 8 group to adjust the spacing of snapping roll hydraulic cylinder and contracting work travel the same value return to the initial state, the pitch adjusting hydraulic cylinder reset to control the hydraulic cylinder header offset contraction of a same value to restore the initial state;

(5) After all the work has been completed, adjust the hydraulic cylinder folded by the cutting table so that both sides of the cutting table of the harvester are folded up again.

(6) The design scheme can realize the cutting platform at most 9 rows of harvesting, and the bias hydraulic cylinder of the cutting table can prevent the structure of the redundant cutting table and the support frame on both sides from extending out, resulting in the lodging of the corn, after the offset of the cutting table hydraulic cylinder is completed, if the 9 rows are not needed to be harvested at the same timeAccording to the actual needs, after adjusting the spacing, to the left as the benchmark for harvesting, the implementation of the cutting table at the same time, the number of lines harvested from 1 to 9 lines. The scheme is flexible and reliable, which facilitates the smooth progress of follow-up work.

(7) The header before work, PLC requires a self checking work is very important, need to check the emergency stop signal is valid, check the hydraulic cylinder is reset to the initial state, after examination, can prompt the header for work, check the program shown in Fig 1.3. 


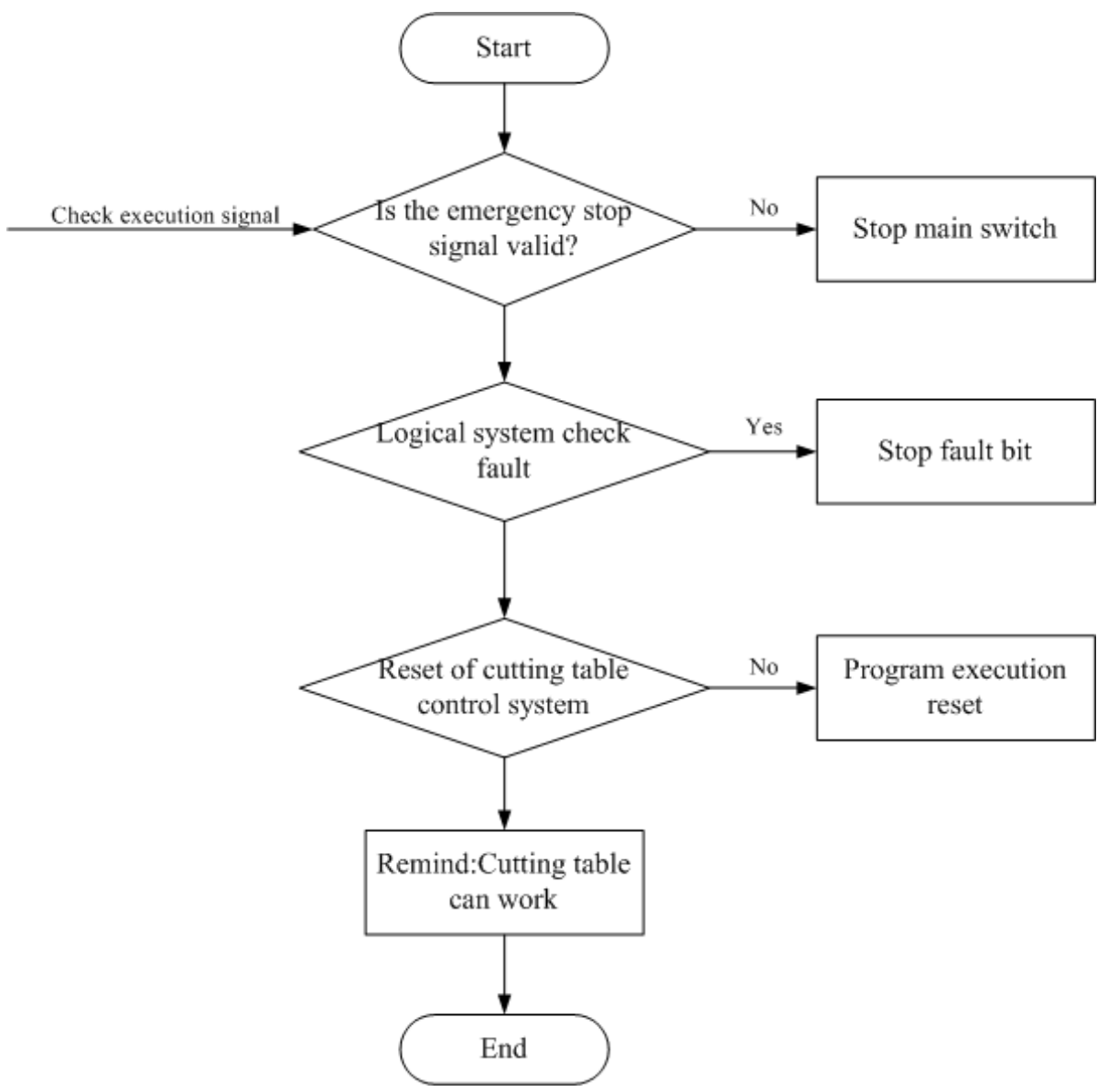

Fig. 1.3 check flow chart before adjustment

The electric control scheme is divided into two modes: manual and automatic. In large farms, the planting area with centralized planting and neatly planting can be greatly improved by using automatic control mode. In small farms, where corn is not planted, plots that need to be regularly regulated can be harvested with manual adjustment to achieve more accurate harvests.

Using the scheme shown in Figure 1.3 to adjust the header row. The control process is simple, because farmers are planting habit, every harvest plots, a spacing can be adjusted, when the harvester in one regional work is completed, the need for reduction work, each re start harvesting need to re adjust the spacing after reset.

\section{Schematic design of electrical equipment}

According to the hydraulic principle diagram of the cutting table, 8 groups of row spacing hydraulic cylinders are divided into two groups. The two groups are A group and B group. According to the electrical control program, according to the control line diagram working principle, draw the electrical principle diagram, as shown in Figure $2.1,0 \mathrm{CH}$ is the input, and $100 \mathrm{CH}$ is the output. 


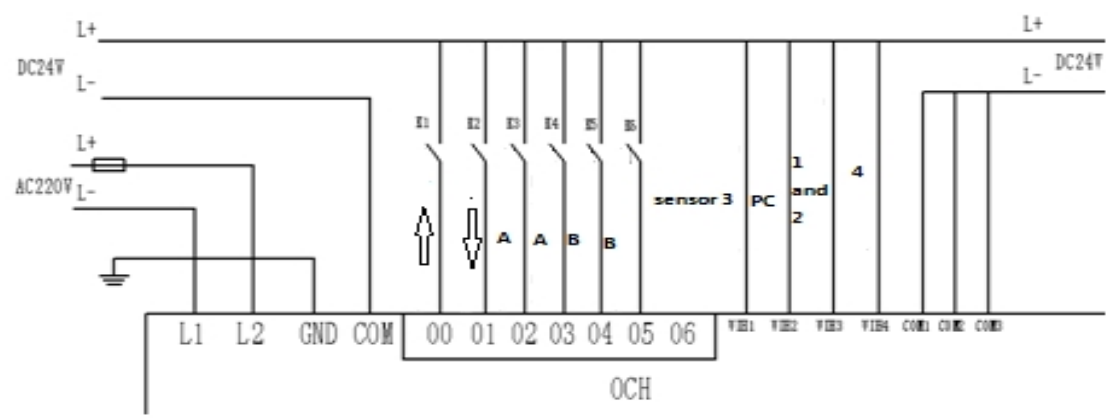

(a) Input

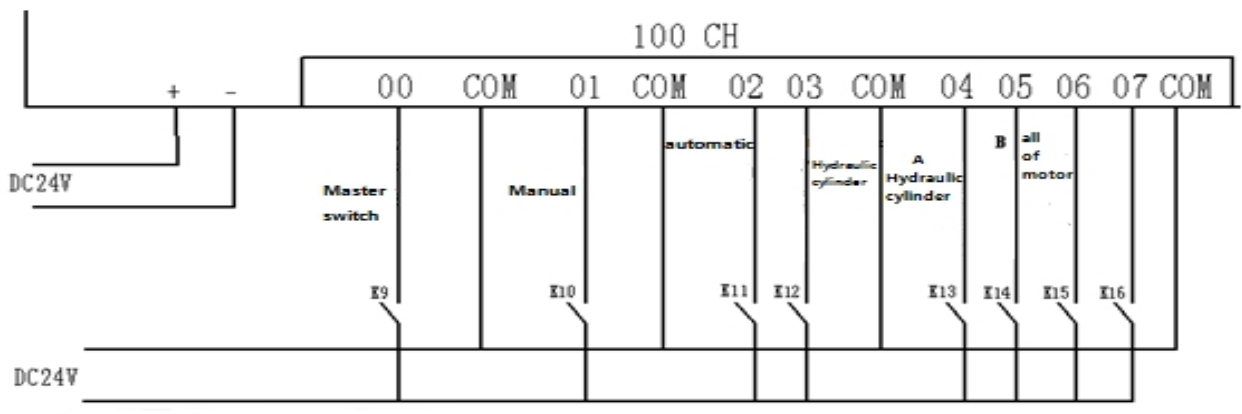

(b)output

Fig. 2.1 schematic diagram of cutting table appliance

\section{Conclusions}

This chapter mainly designs the control scheme of the cutting platform, mainly including hydraulic control scheme and electrical control scheme. The main research results are as follows:

(1) According to the model of corn harvester cutting table needs to realize the function, including rotation rotation and auger cutting table folding, cutting table adjustable row spacing, snapping roll, selection of hydraulic action to implement all the functions, the design of the hydraulic scheme is reasonable and reliable, and according to the actual needs of the corn cutting table hydraulic the need for the selection of components.

(2) New corn harvester, cutting table electric control selects OMRON's PLC, mainly through the control of hydraulic valve opening and closing sequence to control the action of the cutting table. In this chapter, according to the actual needs of the corn cutting platform, the main electrical control hardware configuration is determined, the electrical control scheme is designed, and the simple electrical schematic design is carried out.

\section{Acknowledgements}

This work was financially supported by the Shandong Province, the major project of science and technology (item number: 2015ZDZX10001) " the development and industrialization demonstration of intelligent corn combine harvester" and Taishan industry leading talent project special funds. 


\section{References}

[1] Miu P I, Heinz D K. Simulation of threshing and separation processes in threshing units[J]. Agrartechnische Forschung Sonderheft,2000,(6):1-7.

[2] Miu P I. Mathematical model of material kinematics in an axial threshing unit[J].Computers and Electronics in Agriculture,2007,58(2):93-99.

[3] Miu P I. Mathematical model of threshing process in an axial unit with tangential feeding[J].CSAE. 2002,(2):212-219.

[4] Marchant J A. Tracking of row structure in three crops using image analysis.Comput Electron Agr.1996.15(2):161-179.

[5] Jose A. J. Berni, J. Zarco-Tejada, Lola Suárez, et al. Thermal and Narrowband Multispectral Remote Sensing for Vegetation Monitoring From an Unmanned Aerial Vehicle [J].Transactions on Geoscience and Remote Sensing,2009,47(3):722-738. 